\title{
Can small group education and peer review improve care for patients with asthma/chronic obstructive pulmonary disease?
}

I J M Smeele, R P T M Grol, C P van Schayck, W J H M van den Bosch, $\mathrm{H} J$ M van den Hoogen, J W M Muris

\begin{abstract}
Objective-To study the effectiveness of an intensive small group education and peer review programme aimed at implementing national guidelines on asthma/chronic obstructive pulmonary disease (COPD) on care provision by general practitioners (GPs) and on patient outcomes.
\end{abstract}

Design-A randomised experimental study with pre-measurement and postmeasurement (after one year) in an experimental group and a control group in Dutch general practice.

Subjects and intervention-Two groups of GPs were formed and randomised. The education and peer review group (17 GPs with 210 patients) had an intervention consisting of an interactive group education and peer review programme (four sessions each lasting two hours). The control group consisted of 17 GPs with 223 patients (no intervention).

Centre for Quality of Care Research, Universities of Nijmegen and Limburg, the

Netherlands

I J M Smeele, general practitioner

R P T M Grol, professor

Department of Family Practice, University of Limburg, the

Netherlands

C P van Schayck, professor

Department of Family Practice and Social Medicine, University of Nijmegen, the Netherlands

W J H M van den Bosch, general practitioner, professor

H J M van den Hoogen, statistician

Department of Family Practice, University of Limburg, the

Netherlands

J W M Muris

Correspondence to:

Dr I J M Smeele, Centre for Quality of Care Research,

University of Nijmegen, 229

CEHM PO Box 9101,

6500 HB Nijmegen,

the Netherlands.

Accepted 29 March 1999
Conclusion-Except for two aspects, intensive small group education and peer review in asthma and COPD care do not seem to be effective in changing relevant aspects of the provided care by GPs in accordance with guidelines, nor in changing patients' health status.

(Quality in Health Care 1999;8:92-98)

Keywords: patient outcomes; peer review; asthma; chronic obstructive pulmonary disease; randomised

In the past few decades scientific research has resulted in many new views on diagnosing and treating asthma and chronic obstructive pulmonary disease (COPD) in general practice. For use in actual practice these views have been translated into guidelines and consensus reports. These summarise the best evidence available and contain recommendations on management of these conditions to reduce variation in performance, to tackle underdiagnosis, and to stimulate adequate treatment. ${ }^{1-3}$ Focus is on earlier detection, systematic assessment of lung function through peakflow, prescription of anti-inflammatory medication, and a regular follow up. National guidelines for general practice on asthma/COPD management in adult patients were developed in the Netherlands in line with these ideas on good clinical practice. ${ }^{45}$ The question is how to implement such guidelines and make them work in practice; this will largely depend on the strategies used to disseminate and implement them. Various systematic literature reviews on effective strategies for implementation of guidelines have been published. ${ }^{6-10}$ The main conclusion is that the evidence for many strategies is lacking or confusing, and that a combination of interventions will be most successful in changing performance in practice. ${ }^{11}$

A rigorous analysis of the literature by Grimshaw led to the conclusion that guidelines are most effectively introduced among the target group through interactive methods, involving the care providers actively. ${ }^{6}{ }^{7}$ This links up with the experience in many European countries that small group education and peer review is an effective method for changing general practitioner (GP) performance. ${ }^{12}{ }^{13}$ Good scientific evidence for such a method is, however, largely lacking. Furthermore, little information exists on the effects on patients, which is true for most strategies for changing clinical practice. The review by Grimshaw showed that the effects on patient outcomes were assessed in only $20 \%$ of the included studies. ${ }^{67}$ A controlled study was set up therefore to evaluate the effects of a specially developed small group education and peer review 
In Dutch general practice and in the national guidelines for GPs on asthma/ COPD, no clear distinction was made between asthma and COPD until recently. This is based on the, in the Netherlands broadly accepted, "Dutch hypothesis" which presumes a common aetiological factor in both diseases. ${ }^{14}$ Furthermore, it was not routine activity in general practice to determine lung function. Subsequently, no clear distinction could be made in this study between asthma and COPD. However, since no differences in effects in this study were observed between younger and older patients, a difference in outcome between asthma and COPD seems less probable.

Box 1 Dutch guidelines

programme on the implementation of the national guidelines for general practice. The effects on knowledge, skills, and opinions of GPs, on the care provided as well as on patients symptoms, exacerbations, and quality of life were studied.

\section{Methods}

DESIGN AND SUBJECTS

An experimental study with pre-measurement and post-measurement after one year was set up; the experimental group participated in an intensive interactive group education and peer review programme and the control group received no intervention. GPs $(n=52)$ in the south eastern region of the Netherlands were contacted for participation through their local groups. A balanced distribution in degree of urbanisation and type of practice was aimed at. A total of 34 GPs decided to take part. The 18 non-participating GPs differed significantly in their type of practice $(85 \%$ single handed $v$ $44 \%$ of the participating GPs; $p=0.008 \chi^{2}$ ). Two groups of GPs were formed, equal for type of practice (single handed or not), membership of the Dutch College of General Practitioners, and perceived skills in lung function measurement and inhalation instruction. GPs in the same local group were preferably allocated to the same education group. These groups were allocated at random to the experimental and control modality of the study. GPs were asked to select all known patients with asthma/ COPD in their practice. To reduce underselection this was done in the same way for both groups, with the aid of the researcher through pharmacy lists of all prescribed asthma medication in the previous year. To select patients with asthma/COPD to whom the guidelines would be applicable and who could be expected to have regular contact with the general practice for their asthma or COPD, only those patients were included who had actual complaints or medication use. This was done by using patient questionnaire data. Included were patients aged $\geqslant 25$ years, currently using medication for respiratory complaints or having one of the following symptoms: chronic coughing or expectoration of phlegm; at least one period (minimum three weeks) of coughing or expectoration of phlegm in the past three
- General: aims of the national guidelines; decline of lung function as a risk factor

- Diagnosis: underdiagnosis of asthma/ COPD; discrepancy between complaints and lung function; peakflow and lung function measurement

- Treatment: smoking cessation; indication and use of inhaled medication (bronchodilators, steroids); influenza vaccination

- Follow up: frequency; contents

- Treatment of exacerbations: prescription of antibiotics and short courses of oral steroids

- Patient education: house dust mite eradication and use of written patient information

Box 2 Topics of intensive small group education and peer review programme

years; asthma or complaints of breathlessness during the past year; or asthma attack(s) during the past year. Patients treated by pulmonary physicians or patients with serious comorbidity were excluded.

\section{INTERVENTION}

An intensive, interactive group education and peer review programme, aimed at introducing the national guidelines and containing a combination of specific strategies, was developed and applied. The intervention focused on gaps in adherence to the guidelines, identified in findings of the baseline measurement (box 2). Four sessions lasting two hours each were organised; various strategies for implementing the guidelines were used: lectures, role playing, skills training, peer review of performance, group consensus discussions, and problem solving of hypothetical situations involving patients. The group education and review was done in two small groups (with nine and eight GPs, respectively) and was supervised by an experienced GP. In addition, one educational session was organised for practice assistants from the participating practices, focusing on knowledge of asthma/COPD, peakflow measurement, and inhalation instructions.

\section{INSTRUMENTS AND VARIABLES}

The effect variables were divided into structure, process, and outcome variables (table 1).

\section{Structure}

Structural aspects were measured by a written questionnaire completed by the GPs ${ }^{15}$ : knowledge of management of asthma exacerbations and acute severe dyspnoea (10 questions from an existing questionnaire for GPs in vocational training; score "correct minus wrong") and of inhalation treatment (eight questions, same questionnaire); opinions of GPs on key recommendations from the national guidelines (nine questions (dis)agree); and five questions on the self estimated ability to measure lung function and inhalation instruction (good, a bit, hardly/ not). Finally, there were eight questions (present/not present) on presence of peakflow meters for providing home use to patients (two 
Table 1 Indicators of "quality of asthma care" divided into structure, process, and outcome of care, used as main outcome measures

\begin{tabular}{|c|c|c|}
\hline Structure & Process & Outcome \\
\hline Knowledge & $\begin{array}{l}\text { Actual performance according to guidelines } \\
\text { concerning: }\end{array}$ & Clinical: \\
\hline $\begin{array}{l}\text { Diagnosis and treatment of acute severe } \\
\text { asthma and exacerbations }\end{array}$ & Lung function measurement & Symptoms (severity, exacerbations) \\
\hline Inhalation technique & $\begin{array}{l}\text { Advice on smoking cessation, influenza } \\
\text { vaccination, and house dust mite } \\
\text { eradication }\end{array}$ & Smoking habit \\
\hline Skills in: & $\begin{array}{l}\text { Prescription of anti-inflammatory } \\
\text { medication }\end{array}$ & Functional status: \\
\hline Lung function measurement & Prescription of inhaled medication only & Disease specific quality of life \\
\hline Inhalation instruction & Treatment of exacerbations & \\
\hline Opinion on key features of the guidelines & Patient education & \\
\hline \multicolumn{3}{|l|}{ Equipment for: } \\
\hline \multicolumn{3}{|l|}{ Lung function measurement } \\
\hline \multicolumn{3}{|l|}{ Patient education } \\
\hline Treatment of acute severe dyspnoea & & \\
\hline
\end{tabular}

questions), on education and inhalation instruction materials (two questions), and on equipment for treatment of acute severe dyspnoea (four questions). All items were directly derived form the national guidelines and selected after discussion with co-authors of the national guidelines and experienced GPs.

Process

Process of care was measured through self recording by the GPs of their performance in contacts with patients with asthma/COPD during a period of three months (at least 15 successive contacts were asked for) and through recording of repeat prescriptions for patients with these conditions. Structured self recording sheets were developed for this purpose, containing key elements of the national guidelines. Data were collected on measuring lung function, prescription of inhaled medication, and anti-inflammatory medication; and on the management of exacerbations. Research has shown that this assessment of own performance is a reliable instrument for recording GPs' treatment; the agreement similarity with observations by nonparticipating GPs yielded an average $\kappa$ of $0.76 .{ }^{16}{ }^{17}$ Additional data on the process of care, concerning the advice given on smoking cessation, influenza vaccination, and house dust mite eradication and on patient education provided were collected through written questionnaires completed by the participating patients.

Outcomes

Outcomes of care were measured using data from patient questionnaires. The indicators were derived from the goals of treatment as are formulated in the national guidelines.

- Asthma/COPD symptoms were assessed using the questionnaire of the Dutch Medical Research Council (MRC) ${ }^{18}$ : the presence of chronic cough and chronic phlegm (yes/no); and the degree of dyspnoea (three point scale: no dyspnoea $=0$; dyspnoea when in a hurry $=1$; when walking with others on flat ground=2; having to stop for breath or worse $=3$ ).

- The number of exacerbations was assessed by asking the patient about (duration of) complaints or (changes in) phlegm, cough, dyspnoea, wheezing, and use of bronchodila- tors during the previous three months. An exacerbation was defined as an episode of more than three days with more than three out of the five complaints mentioned. ${ }^{19}$

- Smoking habits were assessed by asking for actual smoking behaviour (yes/no).

- Quality of life was measured by the respiratory illness questionnaire (QOL-RIQ), a selfadministered questionnaire which has been especially developed for use in primary care and validated for patients with asthma, COPD, and emphysema. ${ }^{20}$ The instrument contains 56 items divided over seven subscales on breathing problems (11 items), physical problems (9 items), emotions (9 items), situations triggering/enhancing breathing problems (7 items), daily/domestic activities (10 items), social activities/ relationships and sexuality (6 items), and general activities (4 items). A seven point Likert scale is used. Content validity, construct validity, and internal consistency have been shown to be acceptable in the Dutch population. According to our guidelines, an individual dummy score was introduced in case of missing data (that is, $50 \%$ missing allowed per subscale, one subscale on the whole list).

STATISTICAL ANALYSIS

For the structure and process of care, statistical testing was done for all changes in effect variables between groups as well as for those within groups. Data from the GP questionnaire (binominal paired data) were tested by $\mathrm{McNe}$ mar and $\chi^{2}$ with continuity correction given the low numbers for each cell. In case of normal

Table 2 Characteristics of patients in the education and peer review group and the control group on entry study

\begin{tabular}{lll}
\hline & $\begin{array}{l}\text { Education } \\
\text { and peer } \\
\text { review } \\
\text { group; } \\
n=210(\%)\end{array}$ & $\begin{array}{l}\text { Control } \\
\text { group; } \\
n=223(\%)\end{array}$ \\
\hline Mean age (years) & 52 & 49 \\
Sex (\% men) & 38 & 41 \\
Current smoking & 32 & 31 \\
Current medication use & 91 & 89 \\
Use of inhalation medication & 82 & 83 \\
Use of preventive medication & 32 & 31 \\
$\begin{array}{l}\text { Continuous daily use of }>2 \\
\text { bronchodilators }\end{array}$ & 19 & 17 \\
$\quad \begin{array}{l}\text { Mean duration asthma/COPD } \\
\text { complaints (yrs) }\end{array}$ & 17 & $14^{\star}$ \\
\hline
\end{tabular}

${ }^{\star}$ Difference significant $\mathrm{p}<.05$ (ANOVA). 
Table 3 Change in knowledge, skills, and opinion in accordance with the national guidelines. Values represent baseline score and change (4) (95\% CI)

\begin{tabular}{|c|c|c|c|c|c|c|c|c|}
\hline \multirow[b]{2}{*}{ Structure of care } & \multicolumn{3}{|c|}{ Education and peer review group $(n=17)$} & \multicolumn{3}{|c|}{ Control group $(n=17)$} & \multirow[b]{2}{*}{$\begin{array}{l}\text { Difference in mean } \\
\text { change }(95 \% \mathrm{CI})^{*}\end{array}$} & \multirow[b]{2}{*}{$p$ Value ${ }^{\star}$} \\
\hline & $\begin{array}{l}\text { Baseline } \\
\text { (95\% CI) }\end{array}$ & $\Delta(95 \% C I)$ & p Value & $\begin{array}{l}\text { Baseline } \\
\text { (95\% CI) }\end{array}$ & $\Delta(95 \% C I)$ & p Value & & \\
\hline \multicolumn{9}{|l|}{ Knowledge score on: } \\
\hline $\begin{array}{l}\text { Diagnosis and treatment of } \\
\text { exacerbations }(0-10)\end{array}$ & $3.6(2.4$ to 4.8$)$ & $+1.2(0.0$ to 2.4$)$ & 0.06 & $4.6(3.3$ to 5.7$)$ & $-0.2(-1.5$ to 1.1$)$ & 0.4 & $+0.9(-0.6$ to 2.4$)$ & 0.25 \\
\hline Inhalation treatment $(0-8)$ & $3.7(2.4$ to 5.0$)$ & $+1.3(0.2$ to 2.4$)$ & 0.03 & $4.6(4.0$ to 5.3$)$ & $-0.5(-1.3$ to 0.3$)$ & 0.5 & $+1.1(-0.4$ to 2.6$)$ & 0.15 \\
\hline Skills performance score $(0-5) \dagger$ & $2.85(2.3$ to 3.5$)$ & $+1.2(0.5$ to 1.9$)$ & 0.002 & $2.7(1.9$ to 3.6$)$ & $+0.5(-0.2$ to 1.2$)$ & 0.13 & $+0.8(0.2$ to 1.3$)$ & 0.006 \\
\hline \multicolumn{9}{|l|}{ Opinion score on main topics } \\
\hline from guidelines $(0-9)$ & $6.5(5.5$ to 7.5$)$ & $+1.2(0.7$ to 1.7$)$ & 0.02 & $6.4(5.5$ to 7.2$)$ & $+0.6(-0.2$ to 1.0$)$ & 0.2 & $+0.6(-0.3$ to 1.5$)$ & 0.3 \\
\hline
\end{tabular}

*After correction for baseline value (ANCOVA). †Five items; $0=$ if for no items skill is "good"; 5 = if for all items skill is "good".

distribution, differences in the composite scores, such as "knowledge", "skills", and "opinion", were tested by means of analysis of covariance (ANCOVA). In these analyses corrections for baseline values were calculated by introducing the baseline value as covariate. Data on self recorded performance in consultations (unpaired data) and the patient questionnaire data (paired data) were analysed at GP level. Given the different number of consultations/patients for each GP a score for each GP was calculated from the number of consultations or patients in which the care was provided in accordance with the national guidelines, divided by the total number of consultations or patients of that GP. This was done both at pre-measurement and postmeasurement. ANCOVA was calculated and each time the baseline value was corrected for by introducing the baseline value as covariate.

For patient outcomes it was first investigated whether the patient could be used as the unit of analysis because a nested design was used in which the GPs and not the patients were randomised. ${ }^{21}{ }^{22}$ This randomisation was done at GP level because the intervention was aimed at the GP. Furthermore, it is not possible to randomise patients within one practice because of expected contamination. Analyses taking account of the intraclass correlation (HLM) produced virtually identical results to analyses that ignored it, thus for simplicity only results based on patient analyses are presented here. Differences between baseline values using $\chi^{2}$ and analysis of variance were tested for. Differences between pre-measurement and postmeasurement were tested for normal distribution. Changes in asthma symptoms and smoking habits were tested for within group and between group differences by means of the McNemar and the $\chi^{2}$ test; changes in the number of exacerbations between groups were tested by the distribution free Kruskal-Wallis test for ordinal data, and were tested for within groups with the McNemar test. The differences in the quality of life scores were analysed by ANCOVA, correcting for baseline value by introducing baseline value as covariate. Subgroup analyses were calculated for three groups of patients: patients with complaints not using preventive medication at baseline; more severe patients (patients having at least grade 3 dyspnoea and/or chronic cough and/or chronic phlegm at baseline); and younger versus older patients ( $<55$ years $v \geqslant 55$ years).

For the level of significance $\mathrm{p}<0.05$ was chosen. $^{23}$

\section{Results}

SUBJECTS AND DATA

All 34 GPs completed the written questionnaires before and after measurement. No differences were observed between the two groups for characteristics of GPs, such as age, sex, practice form (single handed versus not single handed), membership of the Dutch College, self estimated skills, and mean number of participating patients for each GP in the study. The make up of the participating GPs did not differ significantly from the national for type of practice ( $44 \%$ single handed $v 54 \%$ national), membership of the Dutch College $(68 \%$ member $v 63 \%$ national), and age distribution.

Two GPs from the experimental group and two GPs from the control group did not record their performance in consultations before and after measurement due to illness $(n=2)$ or lack of motivation $(n=2)$. The remaining 30 GPs recorded 507 GP-patient contacts and 167 repeat prescriptions before measurement (average recording period 3.5 months) and 427 GP-patient contacts and 183 repeat prescriptions at post-measurement (average recording period 3.1 months).

No differences were observed in the number of recorded consultations between the two groups.

Table 4 Change in adherence to the guidelines for presence of equipment in practice. Values represent baseline score and mean change (A)

\begin{tabular}{|c|c|c|c|c|c|}
\hline \multirow[b]{2}{*}{ Structure of care } & \multicolumn{2}{|c|}{$\begin{array}{l}\text { Education and peer review } \\
\text { group }(n=17)\end{array}$} & \multicolumn{2}{|c|}{ Control group $(n=17)$} & \multirow{2}{*}{$\begin{array}{l}p \text { Value of between } \\
\text { group changet }\end{array}$} \\
\hline & Baseline & $\Delta$ & Baseline & $\Delta$ & \\
\hline \multicolumn{6}{|l|}{ Presence of equipment in practice for ${ }^{\star}$} \\
\hline Peakflow measurement & 12 & $+5 \ddagger$ & 9 & +2 & 0.04 \\
\hline Patient education inhalation instruction materials & 15 & +2 & 11 & +2 & 0.4 \\
\hline Treatment of acute severe dyspnoea & 8 & +4 & 9 & +3 & 0.9 \\
\hline
\end{tabular}

$\star$ Values represent change in number of GPs in which these topics were in accordance with the national guidelines. $+\chi^{2}$. $\neq$ Within-group change $\mathrm{p}<.05$ (McNemar). 
Table 5 Change in adherence to the guidelines for non-pharmacological treatment. Values represent baseline score and mean change (4) (95\% CI)

\begin{tabular}{|c|c|c|c|c|c|c|c|c|}
\hline \multirow[b]{2}{*}{ Process of care } & \multicolumn{3}{|c|}{ Education and peer review group $(n=16)$} & \multicolumn{3}{|c|}{ Control group $(n=17)$} & \multirow[b]{2}{*}{$\begin{array}{l}\text { Difference in mean } \\
\text { change }(95 \% \mathrm{CI})^{*}\end{array}$} & \multirow[b]{2}{*}{$p$ Value $^{x}$} \\
\hline & $\begin{array}{l}\text { Baseline } \\
(\%)\end{array}$ & $\Delta(95 \% C I)$ & $p$ Value & $\begin{array}{l}\text { Baseline } \\
(\%)\end{array}$ & $\Delta(95 \% C I)$ & $p$ Value & & \\
\hline \multicolumn{9}{|l|}{ Non-pharmacological general treatment: } \\
\hline Advice on smoking cessation & 63 & $+9 \%(0 \%$ to $19 \%)$ & 0.07 & 59 & $+5 \%(-9 \%$ to $19 \%)$ & 0.5 & $+5 \%(-9 \%$ to $20 \%)$ & 0.5 \\
\hline Flu vaccination & 39 & $-2 \%(-8 \%$ to $4 \%)$ & 0.5 & 35 & $+3 \%(-4 \%$ to $10 \%)$ & 0.4 & $-4 \%(-15 \%$ to $6 \%)$ & 0.4 \\
\hline Advice on house dust mite eradication & 17 & $-2 \%(-6 \%$ to $2 \%)$ & 0.3 & 21 & $+4 \%(-2 \%$ to $10 \%)$ & 0.2 & $-7 \%(-16 \%$ to $2 \%)$ & 0.1 \\
\hline Written patient education & 26 & $+3 \%(-7 \%$ to $13 \%)$ & 0.6 & 21 & $+7 \%(-1 \%$ to $15 \%)$ & 0.1 & $-1 \%(-13 \%$ to $11 \%)$ & 0.8 \\
\hline
\end{tabular}

^After correction for baseline value (ANCOVA).

A total of 891 patients were originally requested to participate by their GPs. After exclusion of those who did not meet the inclusion criteria, data from pre-measurement questionnaires were available for 544 patients. For each GP this was a mean number of 16 patients, which is approximately $50 \%$ of the expected number on the basis of epidemiological data. ${ }^{24}$ The total dropout of patients during the study was $111(20 \%): 46(8 \%)$ had been consulting a pulmonary physician during the study year and the remainder $(n=65,12 \%)$ failed to respond. This resulted in 433 eligible patients whose data could be used in the analysis. Table 2 summarises characteristics of these patients. No significant differences existed between participants and dropouts for these characteristics, nor was there a significant difference between the groups with regard to the number of dropouts. The only significant difference between the groups was duration of the asthma/COPD complaints (14 $v 17$ years; $\mathrm{p}<0.05$ ).

Participation in the meetings for the education and peer review group was as follows: seven out of 17 GPs were present at all four meetings, six GPs attended three meetings, and four GPs were at two or fewer meetings. Twelve out of $17 \mathrm{GP}$ practice assistants from the experimental group attended the group education meeting offered.

\section{Structure of care}

Significant improvements were seen within the education and peer review group in knowledge on inhalation treatment $(+16 \% ; 95 \%$ CI $2 \%$ to $30 \%)$, self estimated skills ( $+24 \% ; 95 \%$ CI $10 \%$ to $38 \%)$, opinion $(+13 \% ; 95 \%$ CI $9 \%$ to $19 \%)$, and the presence of peakflow meters in the practice $(+29 \%$; $\mathrm{p}<0.05)$ (tables 3 and 4$)$. However, only for presence of peakflow meters and skills were the changes significant compared with the control group.

\section{Process of care}

The baseline data of the care in the education and peer review group did not show any difference with those in the control group. In both groups an improvement in provided care was seen; the improvement was most substantial in the education and peer review group. From the 12 selected effect measures in both groups, however, only one showed a significant change within the group (peakflow measurement in follow up of an exacerbation $+26 \%$; $95 \%$ CI $4 \%$ to $48 \%$ ) (tables 5 and 6 ). This change was not significant $(+30 \% ; 95 \%$ CI $-2 \%$ to $61 \%)$ compared with the control group.

\section{Patient outcomes}

No differences existed for the baseline level of patient outcomes in the two groups. No significant improvements were observed in the education and peer review group. In the control group, however, the disease specific quality of life improved on three out of seven subscales (tables 7 and 8). After correction for baseline value these improvements did not differ significantly between the two groups.

\section{Subgroup analysis}

Separate analyses were done excluding the GPs who were only present at two or fewer of the educational sessions. There were only slight differences for all outcome measures, which were only significant for the advice on smoking cessation (+13\%, 95\% CI $1 \%$ to $25 \%)$ and measurement of peakflow at follow up of an exacerbation $(+33 \%, 95 \%$ CI $11 \%$ to $55 \%)$. However, neither were significant compared with the control group.

Table 6 Change in adherence to the guidelines for general pharmalogical treatment and management of exacerbations. Values represent baseline score and change (4) ( $95 \%$ CI)

\begin{tabular}{|c|c|c|c|c|c|c|c|c|}
\hline \multirow[b]{2}{*}{ Process of care } & \multicolumn{3}{|c|}{ Education and peer review group $(n=15)$} & \multicolumn{3}{|c|}{ Control group ( $n=15$ GPs) } & \multirow{2}{*}{$\begin{array}{l}\text { Difference in mean } \\
\text { change }(\%) \\
(95 \% \mathrm{CI})^{\star}\end{array}$} & \multirow[b]{2}{*}{$p$ Value $^{\star}$} \\
\hline & $\begin{array}{l}\text { Baseline } \\
(\%)\end{array}$ & $\Delta(\%)(95 \% C I)$ & $p$ Value & $\begin{array}{l}\text { Baseline } \\
(\%)\end{array}$ & $\Delta(\%)(95 \% C I)$ & $p$ Value & & \\
\hline \multicolumn{9}{|l|}{ General pharmacological treatment: } \\
\hline Prescription of inhalation treatment only & 98 & $+2(-2 \%$ to $5 \%)$ & 0.4 & 95 & $+4(0 \%$ to $8 \%)$ & 0.1 & $-1(-3 \%$ to $1 \%)$ & 0.3 \\
\hline No prescription of xanthines & 94 & $+2(-1 \%$ to $5 \%)$ & 0.2 & 96 & $0(-2 \%$ to $2 \%)$ & 0.9 & $+0.1(-.3 \%$ to $3 \%)$ & 0.9 \\
\hline $\begin{array}{l}\text { Anti-inflammatory medication in case of } \\
>2 \mathrm{td} \text { bronchodilators use }\end{array}$ & 69 & $+11(-5 \%$ to $27 \%)$ & 0.2 & 65 & $+1(-11 \%$ to $13 \%)$ & 0.9 & $+13(-2 \%$ to $27 \%)$ & 0.09 \\
\hline \multicolumn{9}{|c|}{ Exacerbations; performance of peakflow measurement in: } \\
\hline Diagnosis of an exacerbation & 21 & $+16(-2 \%$ to $34 \%)$ & 0.09 & 20 & $+18(9 \%$ to $27 \%)$ & 0.02 & $-2(-21 \%$ to $18 \%)$ & 0.8 \\
\hline Follow up of exacerbation & 37 & $+26(4 \%$ to $48 \%)$ & 0.03 & 47 & $-5(-25 \%$ to $55 \%)$ & 0.9 & $+30(-2 \%$ to $61 \%)$ & 0.2 \\
\hline \multicolumn{9}{|l|}{ Exacerbations; prescription of: } \\
\hline Oral steroids & 21 & $+13(-6 \%$ to $32 \%)$ & 0.2 & 29 & $+4(-11 \%$ to $19 \%)$ & 0.7 & $+5(-19 \%$ to $28 \%)$ & 0.7 \\
\hline Inhaled steroids & 52 & $+13(-1 \%$ to $27 \%)$ & 0.08 & 51 & $-1(-13 \%$ to $14 \%)$ & 0.9 & $+14(-4 \%$ to $32 \%)$ & 0.1 \\
\hline Antibiotics (seldom indicated) & 66 & $-17(-1 \%$ to $34 \%)$ & 0.07 & 64 & $-10(-20 \%$ to $0 \%)$ & 0.06 & $-5(-22 \%$ to $13 \%)$ & 0.6 \\
\hline
\end{tabular}

^After corrections for baseline value (ANCOVA). 
Table 7 Changes in number of people with grade 3 dyspnoea, chronic cough, chronic phlegm, current smoking, and exacerbations in the previous three months (ratio). Values represent baseline value (\%) and change (4) per group

\begin{tabular}{|c|c|c|c|c|c|}
\hline \multirow[b]{2}{*}{ Outcome of care } & \multicolumn{2}{|c|}{$\begin{array}{l}\text { Education and peer review group } \\
(n=210)\end{array}$} & \multicolumn{2}{|c|}{ Control group $(n=223)$} & \multirow[b]{2}{*}{$\begin{array}{l}\text { Between group chang } \\
(p \text { value })^{t}\end{array}$} \\
\hline & $\begin{array}{l}\text { Baseline value } \\
(\%)\end{array}$ & $\Delta^{\star}$ & $\begin{array}{l}\text { Baseline value } \\
(\%)\end{array}$ & $\Delta^{*}$ & \\
\hline Grade 3 dyspnoea & $29(14)$ & -1 & $21(9)$ & +3 & 0.2 \\
\hline Chronic cough & $68(32)$ & -8 & $61(27)$ & -12 & 0.3 \\
\hline Chronic phlegm & $55(26)$ & -7 & $51(23)$ & -4 & 0.4 \\
\hline Current smokers & $68(32)$ & +2 & $69(31)$ & +1 & 0.7 \\
\hline $\begin{array}{l}\text { Exacerbation ratio } \\
(95 \% \mathrm{CI}\end{array}$ & $\begin{array}{l}0.35 \\
(0.24 \text { to } 0.46)\end{array}$ & $\begin{array}{l}0 \\
(-0.1 \text { to } 0.1)\end{array}$ & $\begin{array}{l}0.44 \\
(0.32 \text { to } 0.56)\end{array}$ & $\begin{array}{l}-0.11 \\
(-0.26 \text { to } 0.04)\end{array}$ & 0.1 \\
\hline
\end{tabular}

*All within group changes not significant.

$+\chi^{2} /$ Kruskal-Wallis.

Furthermore, subgroup analyses were calculated for those patients who might particularly benefit of improved care-that is, those who had complaints but did not use preventive medication at entry into the study and those with a more severe condition. No differences in the results were observed between the education and peer review group and the control group. Also, no differences in results were found in the subgroup analyses of different age groups ( $<55$ years, $\geqslant 55$ years).

\section{Discussion}

The results showed that at the time of the study the care that GPs provided to patients with asthma/COPD was already in line with national guidelines for several essential aspects. However, there were also important deviations, for instance for the equipment, knowledge, and skills of GPs and the process of care. At patient level the most important problem seems to be the many patients who smoke.

Developments in the control group showed that without special measures only small changes in care provisions can be achieved. These small changes may have been caused by an "in care" effect or by a secular trend influenced by publication of the guideline. An intensive small group education and peer review programme, which combined various strategies, was proved to influence aspects of knowledge, skills, opinions, and the presence of equipment according to the guidelines, but had, except for one outcome measure, no significant influence on the provided care. Consequently, no changes were observed in the patients' health status and quality of life. The findings in the educational and peer review group support the idea that knowledge, skills, attitudes, and aspects of performance can be promoted to some extent through interactive and intensive small group education, but are not sufficient to be the only strategy used. The method used in this study, including a specially designed education package for implementing national guidelines and reviewing performance within small groups with a GP as tutor, corresponds with this model well. The results are also in line with previous publications. In a review of 99 trials on continuing medical education (CME) activities a positive change in at least one effect measure was found in about two thirds of the studies. ${ }^{25}$ However, it was also concluded that formal CME conferences without enabling or practice reinforcing strategies had little impact. Thus, CME can be seen as a starting point for change but more activities are necessary to really implement changes. Also, as in our results, change in patient outcomes were seen less frequently. Apart from the small changes observed in the process of care and the relatively mild to moderate disease in these patients treated in general practice, as in our study, this infrequent change in outcomes may be caused by factors such as patients not accepting GP recommendations, the socioeconomic and educational status of the patients, and the limited effectiveness of the clinical interventions themselves. ${ }^{26}$

As previously mentioned, studies that evaluated the effects on patient outcomes of introducing a set of guidelines for asthma care in everyday general practice are scarce. ${ }^{7}$ White, however, evaluated implementation of asthma guidelines on patient outcomes. ${ }^{27}$ In a controlled trial (with about 400 patients) he investigated the effectiveness of group education (seven sessions) in groups of GPs during 22 years. Although there was a small (not significant) decline of reported complaints

Table 8 Changes in quality of life scores on QOL-RIQ. Values represent mean change (A) (95\% CI) and baseline score

\begin{tabular}{|c|c|c|c|c|c|}
\hline \multirow[b]{2}{*}{ Outcome of care } & \multicolumn{2}{|c|}{$\begin{array}{l}\text { Education and peer review group } \\
(n=174)^{\star \star}\end{array}$} & \multicolumn{2}{|c|}{ Control group $(n=203) *$} & \multirow{2}{*}{$\begin{array}{l}p \text { Value of difference } \\
\text { in mean changet }\end{array}$} \\
\hline & Baseline value & $\Delta(95 \% C I)$ & Baseline value & $\Delta(95 \% C I)$ & \\
\hline Quality of life (total) $\ddagger$ & 1.98 & $-0.01(-0.09$ to 0.07$)$ & 1.97 & $-0.09^{\star \star}(-0.16$ to 0.02$)$ & 0.2 \\
\hline Respiratory complaints & 2.51 & $-0.09(-0.25$ to 0.07$)$ & 2.58 & $-0.20^{\star \star \star}(-0.32$ to 0.08$)$ & 0.4 \\
\hline Triggering or enhancing situations & 2.25 & $-0.08(-0.18$ to 0.02$)$ & 2.23 & $-0.05(-0.17$ to 0.07$)$ & 0.7 \\
\hline Physical complaints & 1.93 & $+0.01(-0.10$ to 0.12$)$ & 1.96 & $-0.13^{\star \star \star}(-0.21$ to 0.04$)$ & 0.06 \\
\hline General activities & 1.66 & $+0.04(-0.9$ to 0.17$)$ & 1.74 & $-0.15^{\star \star}(-0.27$ to 0.03$)$ & 0.05 \\
\hline General daily activities & 2.07 & $-0.04(-0.14$ to 0.06$)$ & 1.89 & $+0.02(-0.07$ to 0.11$)$ & 0.7 \\
\hline Social activities, sexuality, and relationships & 1.77 & $-0.08(-0.22$ to 0.14$)$ & 1.77 & $-0.04(-0.17$ to 0.09$)$ & 0.2 \\
\hline Emotions & 1.69 & $+0.01(-0.12$ to 0.10$)$ & 1.65 & $-0.10(-0.20$ to 0.0$)$ & 0.1 \\
\hline
\end{tabular}

${ }^{\star}$ Missing values total 56 ; within-group changes: ${ }^{\star \star} \mathrm{p}<.05^{\star \star \star} \mathrm{p}<.01$ (ANOVA)

tAfter correction for baseline value (ANCOVA).

$\ddagger$ Scores from 1 (no impairment at all of quality of life) to 7 (very much impairment). A negative change indicates an improvement. 
within the whole group of patients, no significant differences were seen compared with the control group. The conclusion was that participation in educational activities did not lead to a change in GP behaviour to such an extent that it would influence patient outcome. The results of our study confirm these findings about small group education, even though our programme contained a set of additional, possibly more effective, activities such as discussions, review of performance, and role play.

Some comments need to be made about the methodology. Because of the limited number of participating GPs in both groups, the results are prone to a type II error so that possibly a smaller improvement in GPs' performance would not reach significance. Presuming an equal importance of the selected effect measures, and excluding the two effect measures in which there is no room for improvement (baseline $>95 \%$ in accordance with the guidelines), the average improvement in the provided care (10 effect measures) in the education and peer review group was $9 \%$, and $5 \%$ in the control group. Possibly smaller improvements in GPs' performance could not reach significance. It is, however, questionable what the meaning of such a small improvement is in quality improvement. For patient outcomes, however, given the number of patients, the power of the study was sufficient to detect even small improvements as estimated relevant to patients. ${ }^{28}$

Furthermore, in interpreting the results we should consider the possibility of finding a positive result by pure chance given the many outcome measures and the study's $p$ value of $\mathrm{p}<0.05$. Also, randomisation was not done at patient level. Although there were no significant differences between patient characteristics and baseline outcome measures between the groups, confounding factors, potentially biasing the results, which had not been measured or were unknown cannot be excluded.

Although the power of intervention consisted of four sessions and was specially focused on the main problems in asthma and COPD care, not all GPs participated in all sessions and therefore some received only part of the information and stimuli. Nevertheless, this is reality in most GPs' further education. Because of the workload and the huge amount of important subjects and new guidelines, GPs can usually spend only limited time on each of the subjects. This did not bias the results, however, because a separate analysis without the nonparticipating GPs showed only a small difference in the results.

In conclusion, this study showed the strength, but mostly the limitations, of the model for small group education and peer review nowadays widely used in the Netherlands and other countries. ${ }^{12}$ The model may be helpful in changing knowledge, skills, opinions, and some aspects of performance, but usually will not lead to a considerable change in GPs' performance or to the desired changes in patient outcomes. Additional activities and interventions will be needed to achieve optimal GP care for patients with asthma/COPD. In particular, interventions which focus more directly on specific activities in patient contacts, such as monitoring patients and providing patient specific feedback and reminders, may be effective at this level. ${ }^{71}$ Further research exploring the value of innovative change strategies to fit this hypothesis is crucial. 1 National Heart, Lung, and Blood Institute. International consensus report on diagno

2 British Thoracic Society. Guidelines for management of asthma in adults: I chronic persistent asthma. BMF 1990;301:651-3.

3 British Thoracic Society. Guidelines for the management of asthma in adults: II acute severe asthma. BMF 1990;301: 797-800.

4 Bottema BJAM, Fabels EJ, Van Grunsven PM, et al. NHGStandaard Cara bij Volwassenen: Diagnostiek. [NHGGuideline C.N.S.L.D. in adults: diagnosis] Huisarts Wet 1992;35:430-6.

5 Van der Waart MAC, Dekker FW, Nijhoff S, et al. NHG-standaard Cara bij Volwassenen: Behandeling. [NHG-Guideline C.N.S.L.D. in adults: treatment]. Huisarts Wet 1992;35:437-43.

6 Grimshaw JM, Russel IT. Effect of clinical guidelines on medical practice: a systematic review of rigorous evaluamedical practice: a systematic revic
tions. Lancet 1993;342:1317-22.

7 Grimshaw J, Freemantle N, Wallace S, et al. Developing and implementing clinical practice guidelines. Quality in Health Care 1995;4:55-64.

8 Stein LS. The effectiveness of continuing medical education; eight research reports. F Med Educ 1981;56:103-10.

9 White PT, Pharoah CA, Anderson HR, et al. Randomised controlled trial of small group education on the outcome of chronic asthma in general practice. $\mathcal{F} R$ Coll Gen Pract 1989;39:182-6.

10 Wang VL, Terry P, Flynn BS, et al. Evaluation of continuing medical education for chronic obstructive pulmonary diseases. F Med Educ 1979;54:803-11.

11 Wensing M, Grol R. Single and combined strategies for implementing changes in primary care: a literature review. Int $\mathcal{F}$ Qual Health Care 1994;6:115-32.

12 Grol R. Quality improvement by peer review in primary care: a practical guide. Quality Health Care 1994;3:147-52.

13 Grol R, Lawrence M. Quality improvement by peer review. Grol R, Lawrence M. Quality improvem
Oxford: Oxford University Press, 1995.

14 Sluiter HJ, Koeter GH, De Monchy JGFR, et al. The Dutch hypothesis (chronic non-specific lung disease) revisited. Eur Respir f 1991;4:479-89.

15 Schectman JM, Elinsky EG, Pawlson LG. Self-reported versus actual test ordering behaviour among primary care clinicians. Qual Rev Bull 1992;18:60-2.

16 Spies TH. Data collection on decision making in clinical practice. Routinely medical recording versus specific registration in clinical performance assessment. Preliminary report. Centre for Quality of Care Research. Nijmegen: University of Nijmegen, 1997.

17 Dalhuijsen J, Zwaard AM, Grol RPTM, et al. Het handelen van de huisartsen volgens de standaard otitis media acuta van het Nederlands Huisartsen Genootschap. [The manvan het Nederlands Huisartsen Genootschap. [The manacute middle ear infection] Ned Tijdschr Geneesk 1993;137: acute midde.

18 Van der Lende R, Orie NG. The MRC-ECCS questionnaire on respiratory symptoms (use in epidemiology). Scand $\mathcal{F}$ Respir Dis 1972;53:218-26.

19 Kerstjens HAM, Brand LP, Hughes MD, et al. A comparison of bronchodilator therapy with or without inhaled corticosteroid therapy for obstructive airway disease. $N$ Engl F Med 1992;327:1413-9.

20 Maillé AR, Koning CJM, Zwinderman AH, et al. The development of the 'quality-of-life for respiratory illness questionnaire (QOL-RIQ)': a disease-specific quality-of-life questionnaire for patients with mild to moderate chronic non-specific lung disease. Respir Med 1997;91:297-309.

21 Donner A, Donald A. Analysis of data arising from a stratified design with the cluster as unit of randomization. Stat Med 1987;6:43-52.

22 Donner A, Birkett N, Buck C. Randomization by cluster. Sample size requirements and analysis. Am $\mathcal{f}$ Epidemiol 1981;114:906-14.

23 Perneger TV. What's wrong with Bonferroni adjustments. BMF 1998;316:1236-8.

24 Van de Lisdonk EH, Van den Bosch WJHM, Huygen FJA, et al. Ziekten in de huisartspraktijk. [Diseases in general practice] Utrecht: Bunge, 1994.

25 Davis DA, Thomson MA, Oxman AD, et al. Changing physician performance. A systematic review of the effect of continuing medical education strategies. $\mathcal{F} A M A$ 1995;274: $700-5$.

26 Davis DA, Thomson MA, Oxman AD, et al. Evidence for the effectiveness of CME: a review of 50 randomized controlled trials. $\mathcal{F A M A}$ 1992;268:1111-7.

27 White $\mathrm{P}$, Atherton A, Hewett G, et al. Using information from asthma patients: a trial of information feedback in from asthma patients: a trial of info
primary care. BMf 1995;311:1065-9.

28 Juniper EF, Guyatt GH, Willan A, et al. Determining a minimal important change in a disease-specific quality of life questionnaire. F Clin Epidemiol 1994;47:81-7. 